\title{
Exchange rate changes, banking competition and enterprise innovation output Evidence of listed companies in strategic emerging industries
}

\author{
Yuezhu Jiang ${ }^{1}$ \\ ${ }^{1}$ Dalian Polytechnic University Ganjingzi, Dalian, Liaoning, China
}

\begin{abstract}
Taking the listed companies in strategic emerging industries and selected the companies that constitute the Shanghai Stock Exchange China Strategic Emerging Industry Composite Index as samples, this paper uses provincial panel data from 2012 to 2016 to assess the impact of banking competition and exchange rate changes on the innovative products of strategic emerging companies, and tests the relationship out. The results show that banking competition and exchange rate changes have a significant positive impact on the innovation output of enterprises. From the perspective of enterprise scale, increased competition in the banking industry is more conducive to the innovation output of large enterprises. The smaller the enterprise scale, the more sensitive its innovation output is to exchange rate changes.
\end{abstract}

\section{INTRODUCTION}

In 2013, China began to propose a "new normal" for economic development, from rapid development to highquality development. Innovation is an important way of this transformation, and it is also the driving force for whether enterprises can sustainably develop and survive in this economic situation. From the 2019 data of national key R\&D expenditures, it can be seen that in the first quarter, the country's expenditures have reached 7 billion yuan. Strategic emerging industries have also been designated as key targets. Nearly $67 \%$ of newly declared projects are related to strategic emerging industries. The development of strategic emerging industries is a guarantee for my country's economic growth, and it is also a driving force for realizing the industry's shift from location development to mid-to-high-end development. Therefore, if the innovation of strategic emerging enterprises can be promoted to promote the development of the entire industry, it is an important point that needs to be solved urgently.

However, there is still relatively little research on the factors that may influence the innovation output of strategic emerging enterprises. From the perspective of banking financial development, there are few, most of which are researches on the $R \& D$ investment of innovation in banking competition. The samples used are all listed companies, industrial enterprises, etc. Increasing competition in the banking industry has a positive and significant effect on the R\&D investment of enterprises, but it may be affected by exchange rate changes. By focusing on this phenomenon, this paper hopes to analyze the impact of banking competition and exchange rate changes on the innovation of strategic emerging companies, and provide a reference for financial support for the development of the real economy and promoting the innovative output of strategic emerging companies.

\section{LITERATURE REVIEW}

King and Levine proposed that financial institutions can lead enterprises to carry out innovative activities through low-cost identification, and reduce their risks. ${ }^{[1]}$ Benfratello mentioned that the financing services provided by the banking industry will have a direct impact on the financial aspects and innovative activities of enterprises' R\&D investment. ${ }^{[2]}$ Chinese scholar Mingquan Sheng believes that banking competition can help increase the investment efficiency of enterprises. ${ }^{[3]}$ Yuan Lihua found through a sample of China's manufacturing industry that competition in the banking industry has a positive impact on the R\&D investment of enterprises and improved the technical efficiency of enterprises. Zhang Jinqing and Kan Xibing found that promoting structural changes in the banking industry and promoting competition can alleviate corporate funding difficulties. ${ }^{[4]}$

First, when competition in the banking industry increases, due to the participation of more small and medium banks, compared with the existing large banks, small and medium banks will reduce the threshold requirements for companies with loan needs, such as changing creditworthiness, asset scale, etc. The conditions. This enables companies to reduce the intensity of constraints on obtaining external financing through this measure and increase loan availability. That is, banking competition eases financing constraints. Under such enemy-strength financing constraints, it is easier for

Joslyn3197@outlook.com 
companies to obtain funds, carry out innovation activities, and increase innovation output. Tang Qingquan and Wu Cen found that the difficulty of corporate financing constraints can be alleviated by changing the structure of the banking industry to be more competitive. ${ }^{[5]}$ Jing He found that the competition of financing constraints in the banking industry and the technological innovation of enterprises as an effective path, the degree of competition has increased, financing constraints have become smaller, and technological innovation has been improved. Wang Lun gave a similar conclusion. Zhang Xia proposed that exchange rate changes will inhibit corporate innovation, but regional financial development can alleviate this phenomenon. He Yan pointed out that the fluctuation of the RMB exchange rate has a positive impact on the innovation of enterprises and has a continuing effect on the performance of the innovation cycle of enterprises. Similar Shi Enyi also verified that fluctuations in the real exchange rate can enhance technological innovation and enhance technology spillover effects. Based on this, this article has the following two research hypotheses:

$\mathrm{H}_{1}$ : Banking competition can promote the innovation output of enterprises.

$\mathrm{H}_{2}$ : Exchange rate changes have a positive effect on the innovation of enterprises.

Although domestic small and medium-sized enterprises are very small in scale, their number and proportion cannot be ignored. If you want to achieve the development of the entire strategic emerging industries, you cannot ignore this important group. For the innovation output of an enterprise, there must be an initial investment of funds. Therefore, the degree of competition in the development of the macro environment is an important way for them to improve their current predicament. Hellwing proposed that for banks, considering long-term business partnerships, there will be more restrictions on small-scale enterprises, which will hinder the input and output of small-scale enterprises' innovation, which will affect the overall business Innovation output will have a negative effect. Bian Wenlong The increase in market competition is conducive to the development and growth of small and medium enterprises. ${ }^{[6]}$ Similarly, Hongjuan Dizhi proposed that competition between banks has a positive effect on the change of the scale of SMEs. Dai Maoqing's research found that the innovation and R\&D of small and mediumsized enterprises is motivated by the increased competition from county-level banks. The research of Cai Jing and Dong Yan also concluded that the structure of the more competitive banking industry will have a greater impact on SMEs. From this third research hypothesis:

$\mathrm{H}_{3}$ : When other conditions are fixed, the increased competition in the banking industry has a greater boost to the innovation output of large strategic emerging companies

\section{Materials AND Methods}

\subsection{Sample data and source}

The sample used in this article is a listed company belonging to a strategic emerging industry. A total of 595 representative listed companies in strategic emerging industries constitute the constituent stocks of the China Strategic Emerging Industry Composite Index on the Shanghai Stock Exchange as the initial sample companies. Compared with other listed companies in strategic emerging industries, they can be more representative and cover the types of state-owned and private, large, medium and small strategic emerging companies. Considering the availability of data, the sample time interval is 2012-2016.

The bank-level data all come from the China Banking and Insurance Regulatory Commission. The bank data needed for the research content of this article is matched with the enterprise based on the region as the boundary. However, the financial license information system has the disclosure of financial license information: bank type, management institution type, establishment time, approval time, and location. Download the original license information. Subsequently, through the screening of the type of institutions and the location of the region, we manually collected the number of branches of commercial banks in each region and the number of branches of all commercial banks in each region to complete the data. The company-level data comes from the Guotaian database. At the same time, eliminate *ST companies and corporate data with missing data. The initial observations thus obtained are 2975.

\subsection{Variable definitions}

Enterprise innovation output (Lnpatop). The research of Griliches et al. indicated that patent data is an important data reference for research on technological change, that is, innovation. Zhou Xuan proposed that the number of patent applications as a measure of innovation level is more robust and timely than the number of grants. Zhong Teng and Wang Changyun used the data on the number of patent applications in the China Patent Data Project in 2013 to measure innovation output to better represent technological innovation. ${ }^{[7]}$ This article uses the number of patent applications (utility patents and invention patents) of a company each year as an indicator to measure the innovation output of a company

Banking competition (bankcomp). Considering the availability of data, this article draws on the practices of Liu Wei and Huang Guitian and adopts the market share of the top five banks (CR5), that is, the proportion of the number of branches of the top five banks in the number of branches of all commercial banks in the province. To measure the degree of market competition. The specific calculation method is shown in formula (1) and (2).

$$
C R 5=\sum_{\mathrm{r}=1}^{5}\left(\text { branch }_{r m}^{\prime}\right) / \sum_{R=1}^{N_{m}} \text { branch }_{R M}
$$

bancomp $_{\mathrm{i}, \mathrm{m}}=1-C R 5$ 
Exchange rate changes (Exchange): refer to Ren Yonglei to calculate the actual effective exchange rate of the renminbi exchange rate fluctuations at the provincial level, using the ratio of the province's foreign trade volume to China's foreign trade value as the weight. The specific calculation method is shown in formula (3):

$$
\text { Exchange }=\left(X_{i, t} / \sum_{k=1}^{n} X_{i, t}\right) \text { rer }_{t}
$$

Other control variables: According to the existing literature, the square term of exchange rate changes, company size (Size), corporate cash flow (Cashflow), and corporate nature (Nature) are used as control variables. Among them, the size of the enterprise is calculated by the natural logarithm of the assets of the enterprise at the end of the year, and the cash flow of the enterprise is calculated by the ending balance of operating income/receivables. The nature of the enterprise is calculated as a dummy variable, set to 1 for state-owned enterprises and 0 for non-state-owned enterprises

\subsection{Model construction}

Drawing on the research of Cornaggia et al, construct the following static panel data model to analyze the impact of banking competition on the innovation output of strategic emerging enterprises in my country. ${ }^{[8]}$

Lnpatop $_{i, t}=\alpha+\beta$ Bancomp $_{i, t}+$

$\gamma$ Exchange $_{i, t}+\delta$ Ex $^{2}{ }_{i, t}+\eta$ Size $_{i, t}+\theta$ Cashflow $_{i, t}+\kappa N a$ ture $_{i, t}+\varepsilon$

Among them, $\mathrm{i}$ and $\mathrm{t}$ represent province and time respectively. $\beta, \gamma, \delta, \eta, \theta, \kappa$ are estimated coefficients, and $\varepsilon$ is the error term.

\section{Results}

For the choice of fixed-effects model or random-effects model, HAUSMAN test is performed in each equation to ensure accuracy. To ensure that there is no heteroscedasticity problem, each equation is regressed with robust standard errors. The specific results are shown in Table I.

\subsection{Regression result}

\begin{tabular}{|c|c|c|c|} 
TABLE I. & \multicolumn{1}{c|}{ REGRESSION RESUL } \\
\begin{tabular}{|c|c|c|c|}
\hline & $\mathbf{( 1 )}$ & $\mathbf{( 2 )}$ & $\mathbf{( 3 )}$ \\
\hline \multirow{2}{*}{ Bankcomp } & $9.700^{* * *}$ & $9.455^{* * *}$ & $1.758^{*}$ \\
& $(0.936)$ & $(0.899)$ & $(1.012)$ \\
\hline
\end{tabular}
\end{tabular}

\begin{tabular}{|c|c|c|c|}
\hline & (1) & (2) & (3) \\
\hline Bankcomp & $\begin{array}{c}9.700 * * * \\
(0.936)\end{array}$ & $\begin{array}{c}9.455^{* * *} \\
(0.899)\end{array}$ & $\begin{array}{l}1.758^{*} \\
(1.012)\end{array}$ \\
\hline Exchange & & $\begin{array}{c}0.0155^{* * *} * \\
(0.003)\end{array}$ & $\begin{array}{c}0.0205 * * * \\
(0.007)\end{array}$ \\
\hline $\mathrm{Ex}^{2}$ & & & $\begin{array}{c}-6.53 \mathrm{e}-05^{* *} \\
(2.57 \mathrm{e}-05)\end{array}$ \\
\hline Size & & & $\begin{array}{c}0.671 * * * \\
(0.059)\end{array}$ \\
\hline Cashflow & & & $\begin{array}{c}-0.004^{*} \\
(0.003)\end{array}$ \\
\hline Constant & $\begin{array}{c}2.344 * * * \\
(0.565)\end{array}$ & $\begin{array}{c}-3.226^{* * *} \\
(0.571) \\
\end{array}$ & $\begin{array}{c}13.21 * * * \\
(1.088)\end{array}$ \\
\hline $\begin{array}{c}\text { Observation } \\
\mathrm{s}\end{array}$ & 2975 & 2975 & 2975 \\
\hline $\mathrm{R}$-squared & 0.075 & 0.090 & 0.189 \\
\hline
\end{tabular}

\subsection{Robustness testl}

In order to ensure the accuracy of the results, OLS estimation is used for verification. As shown in Table II. Let's take a look and see that the impact of banking competition on the innovation output of enterprises is still positive and significant, and the impact of exchange rate changes on the innovation output of enterprises is still positive. The trend is the same as the result under the fixed effects model.

TABLE II. ROBUSTNESS TEST

\begin{tabular}{|c|c|c|c|}
\hline & & & \\
\hline & (1) & (2) & (3) \\
\hline Bankcomp & $\begin{array}{c}6.815 * * * \\
(0.650)\end{array}$ & $\begin{array}{c}7.600 * * * \\
(0.682)\end{array}$ & $\begin{array}{c}2.309 * * * \\
(0.635)\end{array}$ \\
\hline Exchange & & $\begin{array}{c}0.00608 * * * \\
(0.000965)\end{array}$ & $\begin{array}{c}0.00739 * * * \\
(0.00242)\end{array}$ \\
\hline $\mathrm{Ex}^{2}$ & & & $\begin{array}{c}-1.83 e-05^{*} \\
(1.23 e-05)\end{array}$ \\
\hline Size & & & $\begin{array}{c}0.695 * * * \\
(0.0366)\end{array}$ \\
\hline Cashflow & & & $\begin{array}{c}- \\
0.00861 * * * \\
(0.00280)\end{array}$ \\
\hline Constant & $\begin{array}{l}-0.603 \\
(0.397)\end{array}$ & $\begin{array}{c}-1.481 * * * \\
(0.441)\end{array}$ & $\begin{array}{c}-13.53 * * * \\
(0.801)\end{array}$ \\
\hline $\begin{array}{c}\text { Observation } \\
\mathrm{s}\end{array}$ & 2975 & 2975 & 2975 \\
\hline R-squared & 0.75 & 0.087 & 0.187 \\
\hline
\end{tabular}

\subsection{Further analysis}

In order to further explore the impact of banking competition and exchange rate changes on the innovation output of enterprises, we conducted sub-samples and studied the scale of enterprises separately.

TABLE III. ENTERPRISE SIZE REGRESSION RESULTS

\begin{tabular}{|c|c|c|c|c|}
\hline & $\mathbf{( 1 )}$ & $\mathbf{( 2 )}$ & $\mathbf{( 3 )}$ & $\mathbf{( 4 )}$ \\
\hline \multirow{2}{*}{ Bankcomp } & Small & Small & Large & Large \\
& $8.110^{* * *}$ & 1.852 & $8.132 * * *$ & $3.112^{* * *}$ \\
& $(1.241)$ & $(1.237))$ & $(1.373)$ & $(0.913)$ \\
\hline \multirow{2}{*}{ Exchange } & $0.0164 * * *$ & $0.0401 * * *$ & $0.00983 * *$ & $0.00739 * *$ \\
& $(0.00399)$ & $(0.00925)$ & $(0.00387)$ & $(0.00324)$ \\
\hline \multirow{2}{*}{ Ex ${ }^{2}$} & & $-0.000135 * * *$ & $-6.53 \mathrm{e}-05 * *$ & $-1.64 \mathrm{e}-05$ \\
& & $(3.40 \mathrm{e}-05)$ & $(2.57 \mathrm{e}-05)$ & $(1.67 \mathrm{e}-05)$ \\
\hline \multirow{2}{*}{ Size } & & $0.720 * * *$ & $0.671 * * *$ & $0.671 * * *$ \\
& & $(0.0754)$ & $(0.059)$ & $(0.0680)$ \\
\hline
\end{tabular}




\begin{tabular}{|c|c|c|c|c|}
\hline & $\mathbf{( 1 )}$ & $\mathbf{( 2 )}$ & $\mathbf{( 3 )}$ & $\mathbf{( 4 )}$ \\
\hline & Small & Small & Large & Large \\
\hline \multirow{2}{*}{ Bankcomp } & $8.110^{* * *}$ & 1.852 & $8.132^{* * *}$ & $3.112^{* * *}$ \\
& $(1.241)$ & $(1.237))$ & $(1.373)$ & $(0.913)$ \\
\hline \multirow{2}{*}{ Cashflow } & & -0.00707 & & $0.671^{* * *}$ \\
& & $(0.00577)$ & & $(0.0680)$ \\
\hline \multirow{2}{*}{ Constant } & $2.344^{* * *}$ & $-3.226^{* * *}$ & $13.21^{* * *}$ & $-13.44^{* * *}$ \\
& $(0.565)$ & $(0.571)$ & $(1.088)$ & $(1.541)$ \\
\hline Observations & 1,670 & 1,670 & 1,305 & 1,305 \\
\hline R-squared & 0.066 & 0.141 & \multicolumn{3}{|c|}{0.070} & 0.125 \\
\hline
\end{tabular}

The return of large and small businesses based on total assets. From Table III, we can see that, generally speaking, for large strategic emerging companies, the competition in the banking industry can have a positive and significant impact on their innovation output (the coefficient is positive). This also provides strong evidence for the first research hypothesis. For small strategic emerging companies, banking competition is also positive for innovation output. Although the coefficients of both are positive and significant, there are differences in size. Large enterprises will be more affected by the competition of the banking industry on their innovation output. This verifies the third research hypothesis of this article. In comparison, among the samples by enterprise size, the large enterprises with the banking competition coefficient have risen to 3.112. This shows that the increase in competition in the banking industry is more conducive to the increase in innovation output of large and small enterprises. From the perspective of exchange rate changes, exchange rate changes have a positive and significant impact on the sub-sample companies. Specifically, for small companies, the innovations of companies that are partially affected by exchange rate changes are more obvious than those of large companies. It shows that the heterogeneity of enterprises' regulations will affect the innovation output of enterprises for exchange rate changes and changes in banking competition.

\section{CONCLUSION AND POLICY IMPLICATIONS}

The measurement of competition in the banking industry found that the competition in the banking industry in our country is improving, which has made good changes compared with the previous possible monopoly. A sample of the listing concept composed of the China Strategic Emerging Industry Component Index of the Shanghai and Shenzhen Stock Exchanges and the Shenzhen Stock Exchange Emerging Component Index is selected, and the main regression is tested for robustness by using the OLS method through the regression of the fixed effects model., And passed the test and got the following conclusions.

(1) Competition in the banking industry is important for the innovative output of strategic emerging companies. Increased competition in the banking industry will stimulate the innovation output of enterprises. That is, an appropriate increase in the degree of competition in the banking industry can have a positive incentive and pull effect on the overall innovation output of the enterprise.
(2) The impact of exchange rate changes on the innovation of strategic emerging companies is also worthy of attention. Appropriate changes in the exchange rate have a positive and significant stimulating effect on increasing the innovation output of strategic emerging industries.

(3) Divide the size of the enterprise, and the total assets at the end of the year are lower than the average value as small enterprises, and those with greater than the average value are large enterprises. Regression is performed on sub-samples. Compared with small and medium-sized strategic emerging enterprises, medium and large-scale strategic emerging enterprises have significantly increased competition in the banking industry. That is, as the degree of competition in the banking industry increases, the innovation output of large strategic emerging companies will increase more. In terms of exchange rate changes, small companies are more sensitive, that is, when exchange rate changes increase, the innovation output of small strategic emerging companies increases more rapidly.

Strategic emerging enterprises are now one of the main driving forces driving my China's economic development, and the improvement of their innovation level is of great significance. According to relevant conclusions, it is possible to promote the orderly competitiveness of the banking industry, enhance government guidance, increase attention to enterprises, especially to ease the financing constraints of small and medium-sized enterprises, promote the development of strategic emerging enterprises, and further create sound credit System, strengthen the connection with SMEs, expand the scope and efficiency of financial services, strengthen financial support to the real economy, and promote the development of strategic emerging industries.

\section{REFERENCES}

1. King R. G., Levine R.. Finance, entrepreneurship and growth[J].Journal of Monetary Economics,vol. 32(3), pp. 513-542, 1993.

2. Benfratello L., Schiantarelli F., Sembenelli A. Banks and innovation: microeconometric evidence on italian firms. Journal of Financial Economics, vol.90(2),pp. 197-217,2008,

3. Sheng Mingquan, Zhou Jie, Wang Shun. Banking industry competition and corporate investment efficiency. Journal of Capital University of Economics and Business, vol. 20 (04),pp. 94-104, 2018. 
4. Zhang Jinqing, Kan Xibing. Can banking competition ease the financing constraints of SMEs?. Economics and Management Research, vol.39 (04), pp. 42-54, 2018.

5. Tang Qingquan, Wu Cen. Banking industry structure and financing constraints of corporate innovation activities. Financial Research, vol. 07, pp. 116134,2015

6. Bian Wenlong, Shen Yan, Shen Minggao. Competitiveness of the Banking Industry, Policy Incentives and SME Loans-Evidence from Financial Institutions in 14 Provinces and 90 Counties. Financial Research, vol .01, pp. 114-129, 2017.

7. Zhong Teng, Wang Changyun. Financial Development and Enterprise Innovation Output
Based on the Comparative Perspective of Different Financing Models. Financial Research, vol. 12, pp. 127-142, 2017.

8. Cornaggia J, Mao Y, Tian X,.Does banking competition affect innovation?.Social Science Electronic Publishing.

9. Rajan and G. Raghuram. Insiders and outsiders: the choice between informed and Arm's-length debt. The Journal of Finance, vol. 47(4), pp. 1367-1400, 1992.

10. Brandt L, Li H. Bank discrimination in transition economies: ideology, information, or incentives?.Journal of Comparative Economics, vol. 31(3),pp. 387-413,2003. 